\title{
Novel Control Strategy to Improve Photovoltaic System Performance under Low Irradiance Level
}

\author{
Chang-Hua Lin, ${ }^{1}$ Hwa-Dong Liu, ${ }^{2}$ and Shiue-Der $\mathrm{Lu}^{3 *}$ \\ ${ }^{1}$ Department of Electrical Engineering, National Taiwan University of Science and Technology, \\ No. 43, Sec. 4, Keelung Rd., Da'an Dist., Taipei City 106, Taiwan (R.O.C.) \\ ${ }^{2}$ Circular Line Operations Division, Taipei Rapid Transit Corporation, \\ No. 7, Lane 48, Sec. 2, Zhongshan N. Rd., Zhongshan Dist., Taipei City 104, Taiwan (R.O.C.) \\ ${ }^{3}$ Department of Electrical Engineering, National Chin-Yi University of Technology, \\ No. 57, Sec. 2, Zhongshan Rd., Taiping Dist., Taichung City 411030, Taiwan (R.O.C.)
}

(Received December 17, 2020; accepted June 8, 2021; online published June 11, 2021)

Keywords: maximum power point tracking, solar power, irradiance change per unit area threshold control

A novel algorithm for maximum power point tracking (MPPT) in solar power generation systems was proposed and compared with the conventional methods of hill climbing (HC) and perturbation and observation ( $\mathrm{P} \& \mathrm{O})$ algorithms. The two conventional algorithms are prone to divergence under low irradiance levels $\left(<150 \mathrm{~W} / \mathrm{m}^{2}\right)$, resulting in difficulties in MPPT. The MPPT technique proposed in this study integrates irradiance change per unit area threshold control (ICPUATC) into the $\mathrm{P} \& \mathrm{O}$ algorithm. The proposed algorithm can facilitate quick and precise convergence at the maximum power point (MPP) for a photovoltaic module under a low irradiance level of $65 \mathrm{~W} / \mathrm{m}^{2}$. The proposed and $\mathrm{HC}$ algorithms were compared for irradiance levels of 480,140 , and $65 \mathrm{~W} / \mathrm{m}^{2}$, and the proposed algorithm consistently yielded better results than did the $\mathrm{HC}$ algorithm.

\section{Introduction}

Solar power greatly reduces environmental pollution as it does not emit greenhouse gases or air pollutants. Solar power has been widely used in various fields, including power banks, smartphones, cars, and wireless networks, as well as industrial power (e.g., motor and water pumps) and building power. ${ }^{(1-4)}$ Solar power has provided much convenience in people's lives.

However, solar power has two major shortcomings. First, its output is poor during cloudy days with an irradiance level of less than $150 \mathrm{~W} / \mathrm{m}^{2}$. (5) Second, solar power output depends greatly on climatic factors such as irradiance level and temperature. ${ }^{(6)}$ A maximum power point tracking (MPPT) controller is thus indispensable for enhancing solar power efficiency.

Numerous algorithms have been extensively investigated and are available for the MPPT of solar energy. ${ }^{(7-17)}$ The hill climbing (HC) and perturbation and observation (P\&O) algorithms have been widely used as they are simple and cost-effective. ${ }^{(10,16,17)}$ However, they have four main drawbacks: (1) slow convergence near the maximum power point (MPP), ${ }^{(7)}(2)$ when the 
irradiance is steady, the tracked power point oscillates around the MPP and causes power loss in the system, ${ }^{(7-9,11,12)}$ (3) on cloudy days (irradiance level $<150 \mathrm{~W} / \mathrm{m}^{2}$ ), both algorithms have difficulties in accomplishing MPPT, ${ }^{(7,9,12)}$ (4) when the irradiance changes rapidly, both algorithms are prone to divergence. ${ }^{(8,10)}$

Here, we propose a novel MPPT algorithm for solar power generation systems, which is based on the $\mathrm{P} \& \mathrm{O}$ algorithm integrated with irradiance change per unit area threshold control (ICPUATC). The proposed algorithm can achieve quicker and more precise detection of the MPP, and improve the efficiency of photovoltaic (PV) modules on cloudy days. Experimental results for a PV module under irradiance levels of 480, 140, and $65 \mathrm{~W} / \mathrm{m}^{2}$ confirm that the proposed algorithm has better performance, higher reliability, and greater suitability than the $\mathrm{HC}$ algorithm.

\section{HC Algorithm}

The $\mathrm{HC}$ algorithm is popular owing to its simplicity and low cost. By using sensors to measure the output voltage $\left(V_{p v}\right)$ and output current $\left(I_{p v}\right)$ of a PV module, the $\mathrm{HC}$ algorithm is able to calculate its output power $\left(P_{p v}\right)$. It involves disrupting the duty cycle of a power converter to affect $P_{p v}$ for MPPT. ${ }^{(18)}$ However, the disruptive character of the algorithm causes the actuating point to oscillate around the MPP, resulting in suboptimal power output. In addition, the algorithm compares the power points only with the adjacent power points. Hence, when an actuating point is trapped near a local minimum, divergence may occur (Fig. 1). ${ }^{(13)}$

\section{Proposed Algorithm}

Figure 2 shows a flowchart of the $\mathrm{P} \& \mathrm{O}$ algorithm, which has a simple structure and uses voltage and current sensors to measure the output voltage $V_{p v}$ and output current $I_{p v}$ of a PV module for calculating its output power $P_{p v}$.

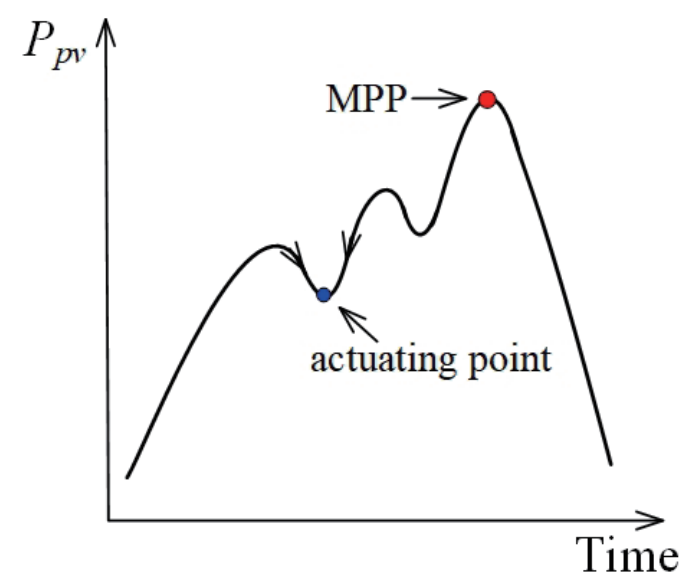

Fig. 1. (Color online) Actuating point trapped near a local minimum in the $\mathrm{HC}$ algorithm. 


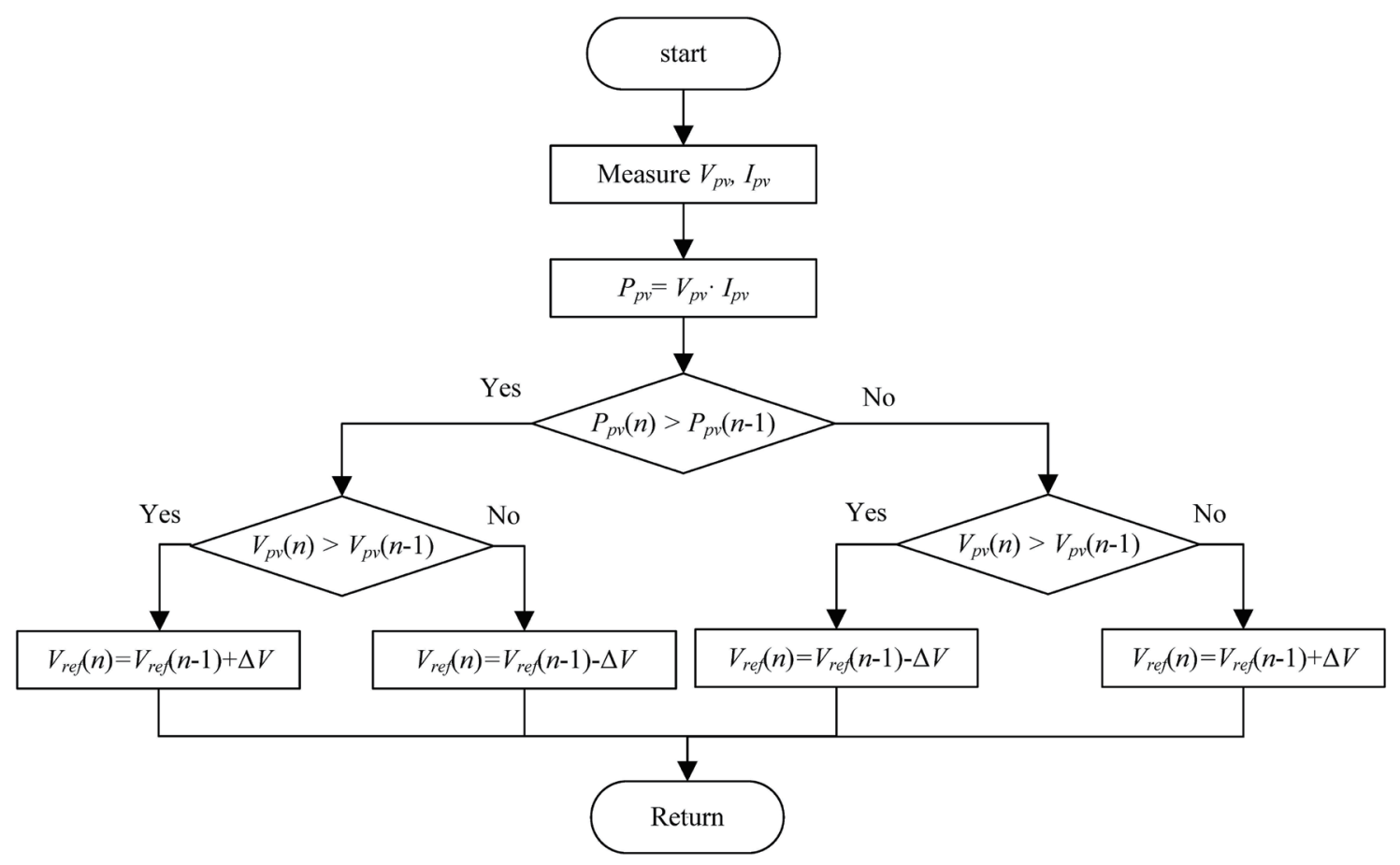

Fig. 2. $\mathrm{P} \& \mathrm{O}$ algorithm flowchart.

As shown in Fig. 2, if $P_{p v}(n)>P_{p v}(n-1)$ and $V_{p v}(n)>V_{p v}(n-1)$, then $V_{r e f}(n)=V_{\text {ref }}(n-1)+\Delta V$. On the contrary, if $V_{p v}(n) \leq V_{p v}(n-1)$, then $V_{\text {ref }}(n-1)=V_{\text {ref }}(n-1)-\Delta V$. If $P_{p v}(n) \leq P_{p v}(n-1)$ and $V_{p v}(n)>V_{p v}(n-1)$, then $V_{r e f}(n)=V_{r e f}(n-1)-\Delta V$. On the contrary, if $V_{p v}(n) \leq V_{p v}(n-1)$, then $V_{\text {ref }}(n)=V_{\text {ref }}(n-1)+\Delta V$.

The P\&O algorithm is based on the $P_{p v}-V_{p v}$ characteristic curve of a PV module with the characteristics of oscillation of the tracked power point around the MPP and the subsequent system power loss. ${ }^{(19)}$ To improve the $\mathrm{P} \& \mathrm{O}$ technique in the case of continuous disturbance, the strategies proposed in this work are as follows: (1) When the slopes of $d P_{p v}$ and $d V_{p v}$ are 0 , a fixed point of the track is located at the MPP and the duty cycle $D$ is fixed. (2) ICPUATC is added to the $\mathrm{P} \& \mathrm{O}$ technique.

\subsection{Relationship between $R_{p v}{ }^{-1}$ and $I_{p v}$}

When the proposed algorithm executed in MPPT reaches the MPP and enters ICPUATC, then Eq. (1) for the impedance $R_{p v}$ of the PV module is satisfied. Equation (1) is the basis of the proposed algorithm to calculate the real irradiance level.

$$
R_{p v}=\frac{V_{p v}}{I_{p v}}
$$


The PV module used in this work (Sanyo, model number HIP-205NKHB5) has the following specifications: short circuit $I_{s c}=5.55 \mathrm{~A}$, open-circuit voltage $V_{o c}=50.5 \mathrm{~V}$, maximum power voltage $V_{M P P}=41 \mathrm{~V}$, maximum power current $I_{M P P}=5 \mathrm{~A}$, and maximum power $P_{M P P}=205 \mathrm{~W}$. Two PV modules were placed in parallel during the experiment, hence, $V_{M P P}=41 \mathrm{~V}, I_{M P P}=10$ $\mathrm{A}$, and $P_{M P P}=410 \mathrm{~W}$.

Trend lines were plotted (in Microsoft Excel) on the relationship between $I_{p v}$ and $R_{p v}{ }^{-1}$, as indicated by Figs. 3(a) and 3(b). Three further trend lines were then drawn (Fig. 4) to display the relationship between $I_{p v}$ and $R_{p v}{ }^{-1}$. In Fig. 4, line A represents a temperature of $0{ }^{\circ} \mathrm{C}$ and irradiance levels of $0-1000 \mathrm{~W} / \mathrm{m}^{2}$, line B represents temperatures between 0 and $75{ }^{\circ} \mathrm{C}$ and irradiance levels of $0-1000 \mathrm{~W} / \mathrm{m}^{2}$, and line $\mathrm{C}$ represents a temperature of $75{ }^{\circ} \mathrm{C}$ and irradiance levels of $0-1000 \mathrm{~W} / \mathrm{m}^{2}$. The following quadratic equation represents the mathematical model and approximates the three trend lines:

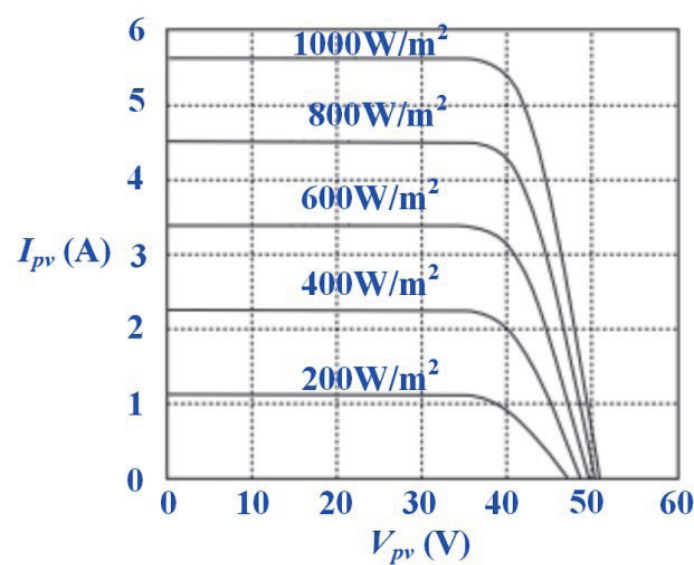

(a)

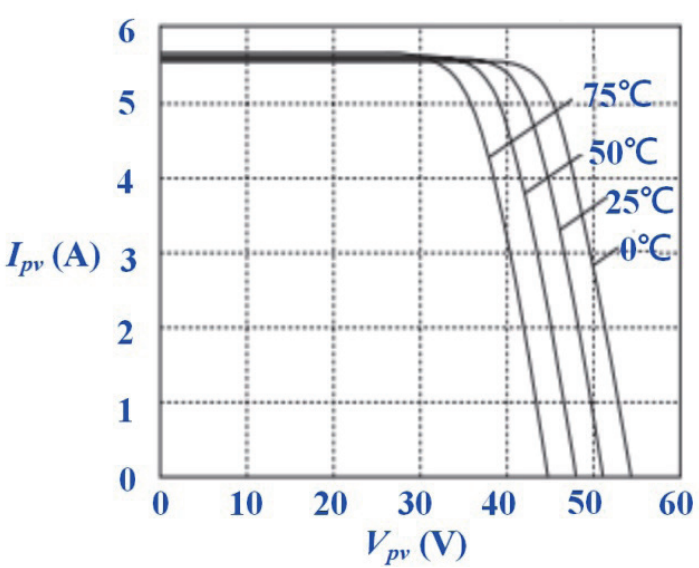

(b)

Fig. 3. (Color online) $I_{p v}-V_{p v}$ characteristic curves for a single PV module (Sanyo, model number HIP205NKHB5). (a) Temperature of $25^{\circ} \mathrm{C}$; irradiance levels of $200,400,600,800$, and $1000 \mathrm{~W} / \mathrm{m}^{2}$. (b) Irradiance level at $1000 \mathrm{~W} / \mathrm{m}^{2}$; temperatures at $0,25,50$, and $75^{\circ} \mathrm{C}$.

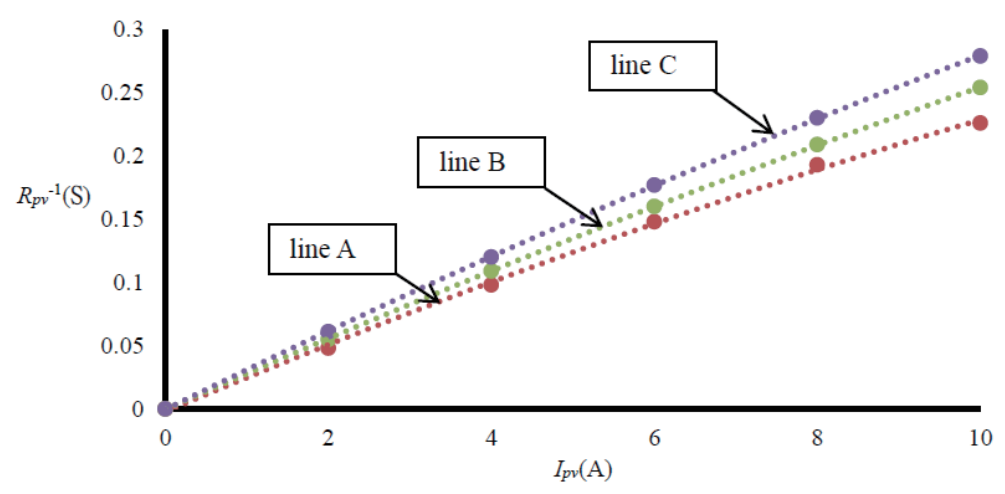

Fig. 4. (Color online) Relationship between $R_{p v}{ }^{-1}$ and $I_{p v}$. 


$$
R_{p v}^{-1}=a\left(I_{p v}\right)^{2}+b\left(I_{p v}\right)+C
$$

Equation (2) can be used to obtain $I_{p v}$.

$$
I_{p v}=\frac{-b \pm \sqrt{b^{2}-4\left[a\left(c-R_{p v}^{-1}\right)\right]}}{2 a}
$$

In Fig. 4, line A was drawn with Eq. (3) using $a=-0.0004, b=0.0273$, and $c=-0.0022$, line B was drawn with $a=-0.0003, b=0.0286$, and $c=-0.0004$, and line $\mathrm{C}$ was drawn with $a=-0.0004, b=0.0317$, and $c=-0.0004$.

A comparison of the three trend lines in Fig. 4 shows that (1) the mean deviations of lines A and $\mathrm{C}$ from line B are less than 5\%; (2) the current $\left(I_{p v}\right.$, Curve 2$)$ based on line B has a $2.5 \%$ margin of error and can be calculated using Eq. (3); (3) if $I_{p v}>1.025 I_{p v}$, Curve2, it falls in the interval of line A; if $I_{p v}<0.975 I_{p v, \text { Curve2 }}$, it falls in the interval of line C; otherwise, it falls in the interval of line B.

\subsection{Relationship between irradiance level $G$ and $R_{p v}{ }^{-1}$}

Trend lines were plotted using Microsoft Excel based on the relationship between $G$ and $R_{p v}{ }^{-1}$, as shown in Figs. 5(a) and 5(b). The three trend lines in Fig. 5 indicate the relationship between $G$ and $R_{p v}{ }^{-1}$ : line A.1 indicates a temperature of $0{ }^{\circ} \mathrm{C}$ and irradiance levels of $0-1000 \mathrm{~W} / \mathrm{m}^{2}$; line B.1 indicates average temperatures between 0 and $75{ }^{\circ} \mathrm{C}$ and irradiance levels of $0-1000 \mathrm{~W} / \mathrm{m}^{2}$; and line C.1 indicates a temperature of $75^{\circ} \mathrm{C}$ and irradiance levels of $0-1000 \mathrm{~W} / \mathrm{m}^{2}$.

The following quadratic equation represents the mathematical model and approximates the above three trend lines:

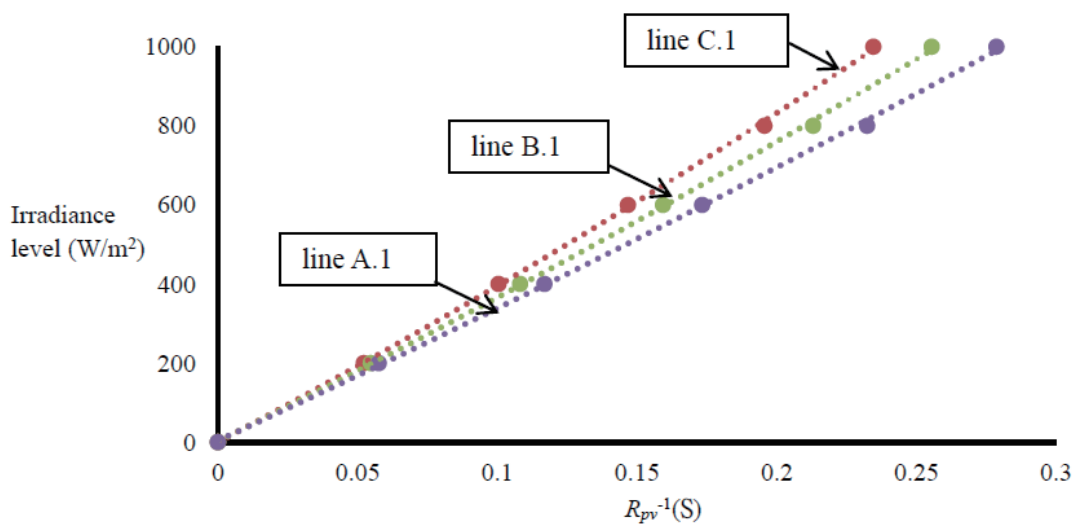

Fig. 5. (Color online) Relationship between irradiance level $(G)$ and $R_{p v}{ }^{-1}$. 


$$
G=d\left(R_{p v}^{-1}\right)^{2}+e\left(R_{p v}^{-1}\right)+f
$$

In Fig. 5, line A.1 was drawn with Eq. (4) using $d=1105.5, e=3231.7$, and $f=4.48$, line B.1 was drawn using $d=1528.6, e=3483$, and $f=2.5075$, and line C.1 was drawn using $d=2120.2$, $e=3735.5$, and $f=0.5798$.

If the values of $R_{p v}{ }^{-1}$ and $I_{p v}$ fall on line A in Fig. 4, they correspond to line A.1 in Fig. 5 and the irradiance value $G$ can be calculated using Eq. (4). Likewise, if the values of $R_{p v}{ }^{-1}$ and $I_{p v}$ fall on line B or C in Fig. 4, they correspond to line B.1 or C.1 in Fig. 5, respectively, and $G$ can be calculated using Eq. (4).

\subsection{ICPUATC}

In this work, the ICPUATC value was set at $1 \mathrm{~W} / \mathrm{m}^{2}$. This value was selected after testing; a very large value led to a slow response of MPPT and a very small value led to a fast response of MPPT. When MPPT could not run at the MPP, power loss occurred.

\subsection{Flowchart of the proposed algorithm description}

Figure 6 shows a flowchart of the proposed algorithm, where $V_{p v}(n)$ is the present voltage, $V_{p v}(n-1)$ is the previous voltage, $I_{p v}(n)$ is the present current, $P_{p v}(n)$ is the present power of the PV module, $P_{p v}(n-1)$ is the previous power of the PV module, $G(n)$ is the present irradiance, $G(n-1)$ is the previous irradiance, $R_{p v}{ }^{-1}(n)$ is the present equivalent conductance, $R_{p v}{ }^{-1}(n-1)$ is the past equivalent conductance, and $D$ is the PWM duty cycle during MPPT.

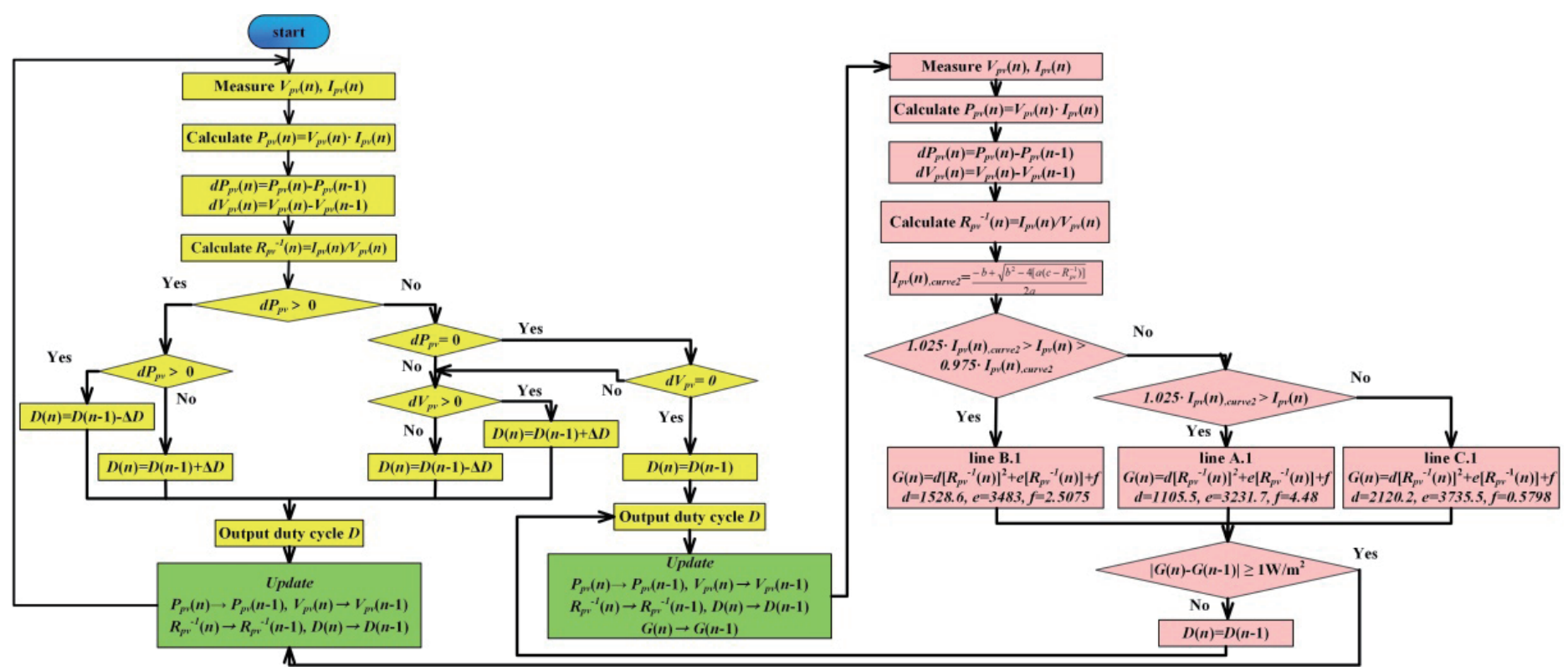

Fig. 6. (Color online) Flowchart of the proposed algorithm. 


\section{Experimental Results}

Figure 7 illustrates the system framework of a boost converter using the proposed algorithm, which is used to compare the proposed algorithm and the HC algorithm. ${ }^{(20-23)}$ The boost converter had an inductance $L$ of $1 \mathrm{mH}$ and an output capacitance $C_{\text {out }}$ of $220 \mu \mathrm{F}$. The microcontroller unit (MCU) used in this work was the 18F452 model manufactured by Microchip Technology. This actual test circuit used an optical coupler as a $V_{p v}$ sensor and a current transducer as an $I_{p v}$ sensor.

The performance of the proposed algorithm under various irradiance conditions was verified by conducting experiments under irradiance levels of 480,140 , and $65 \mathrm{~W} / \mathrm{m}^{2}$. It was observed that the proposed algorithm yielded better results than the $\mathrm{HC}$ algorithm, as shown in Figs. 8-10 and Table 1.

Figure 8 shows the waveforms of the PV output when the proposed and $\mathrm{HC}$ algorithms were employed in the MPPT controller with the PV module under the irradiance of $480 \mathrm{~W} / \mathrm{m}^{2}$ and a temperature of $35^{\circ} \mathrm{C}$. Figure 8 (a) shows the test results of the proposed algorithm. The proposed MPPT algorithm was activated at time $t_{0}$. After the $V_{p v}$ and $I_{p v}$ sensors transmitted measurement signals to the MCU, the MCU performed MPPT calculation, then sent out a PWM signal to control the power MOSFET $S_{1}$ (Fig. 7). In contrast to the HC algorithm, at time $t_{1}$, the proposed method could maintain a fast and stable performance at the MPP.

When the conductance of the PV module $R_{p v}{ }^{-1}$ was $0.13 \mathrm{~S}$, then $I_{p v}$, Curve2 was $4.8 \mathrm{~A}$ from Eq. (3), compared with the measured $I_{p v}$ of $4.7 \mathrm{~A}$. Because $1.025 \cdot I_{p v}$, Curve2 $>I_{p v}>0.975 \cdot I_{p v}$, Curve2 , $I_{p v}$ falls on line B (Fig. 4), which corresponds to line B.1 (Fig. 5). Equation (4) is used to calculate the irradiance $G$, which is $480 \mathrm{~W} / \mathrm{m}^{2}$.

Figure 8(b) shows the test results of the HC algorithm, for which MPPT was activated at time $t_{0}$. After the proposed MPPT algorithm was activated at time $=t_{0}$ and the $V_{p v}$ and $I_{p v}$ sensors

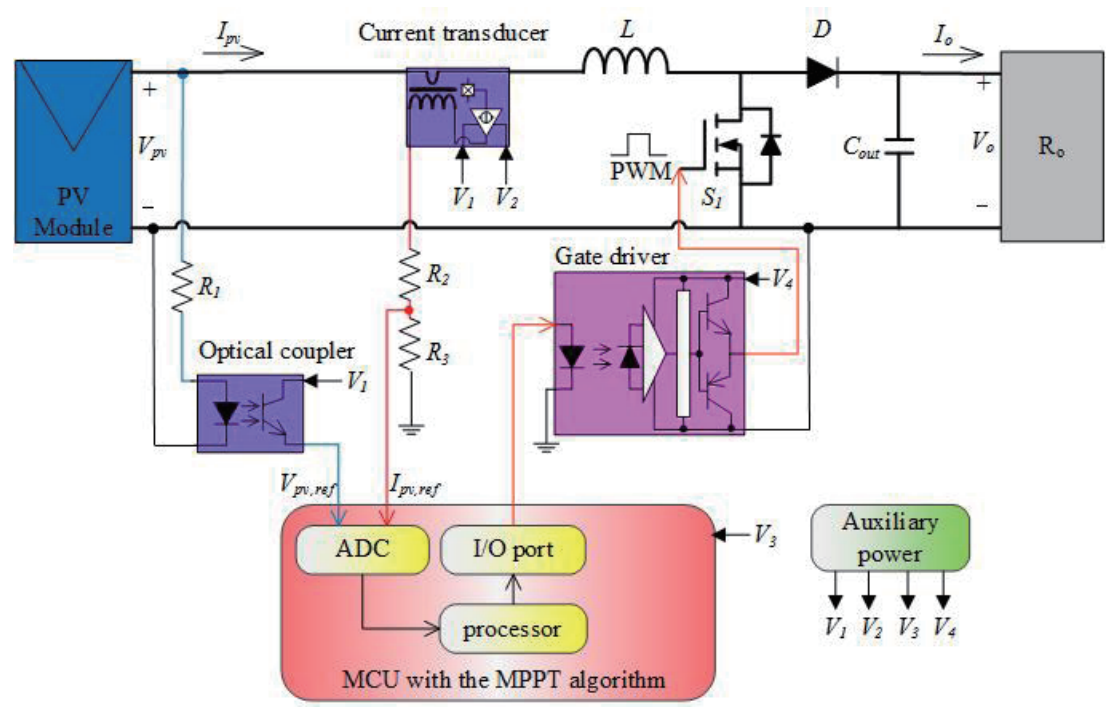

Fig. 7. (Color online) Diagram of the boost converter with the embedded MPPT algorithm. 


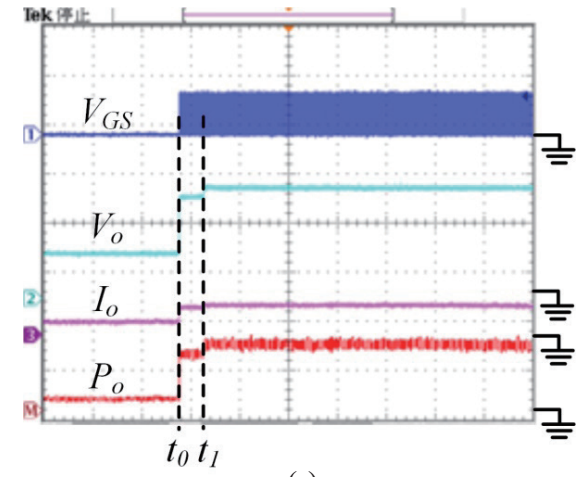

(a)

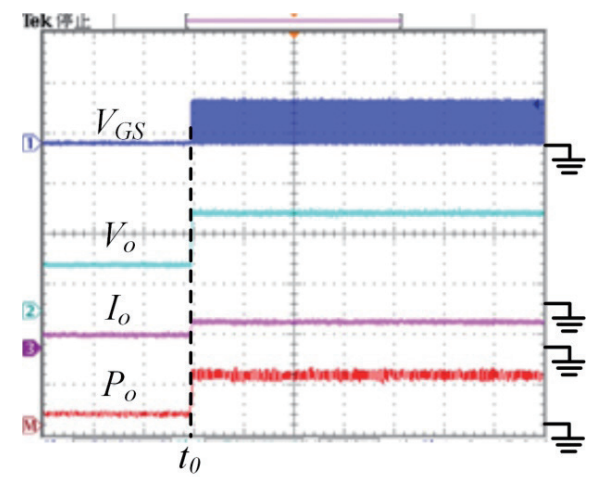

(b)

Fig. 8. (Color online) Waveforms of the gate-source voltage $V_{G S}$ in the MOSFET and the output voltage $V_{o}$, output current $I_{o}$, and output power $P_{o}$ for the PV module under $480 \mathrm{~W} / \mathrm{m}^{2}$ irradiance for the proposed algorithm (a) and the $\mathrm{HC}$ algorithm (b). (Ver: $20 \mathrm{~V} / \mathrm{div}$ for $V_{G S} ; 50 \mathrm{~V} / \mathrm{div}$ for $V_{o} ; 1 \mathrm{~A} / \mathrm{div}$ for $I_{o} ; 50 \mathrm{~W} / \mathrm{div}$ for $P_{o}$, and Hor: $2 \mathrm{~s} / \mathrm{div}$ ).

delivered measurement signals to the MCU, the MCU executed the MPPT calculation, then sent out a PWM signal to drive the power MOSFET $S_{1}$ (Fig. 7). It was observed that the tracked power point of the $\mathrm{HC}$ algorithm oscillated around the MPP, which led to power loss of the system. The experimental results in Table 1 verify that the proposed algorithm yielded higher MPPT efficiency and greater output power $P_{o}$ than did the HC algorithm.

Figure 9 illustrates the waveforms of the PV output when the proposed and $\mathrm{HC}$ algorithms were used in the MPPT controller for the PV module under irradiance of $140 \mathrm{~W} / \mathrm{m}^{2}$ and a temperature of $25^{\circ} \mathrm{C}$. Figure 9(a) shows the test results of the proposed algorithm. The proposed MPPT algorithm was activated at time $t_{0}$. Following the transmission of measurement signals from the $V_{p v}$ and $I_{p v}$ sensors to the MCU, the MCU performed the MPPT calculation then sent out a PWM signal to drive the power MOSFET $S_{1}$ (Fig. 7). In contrast to the HC algorithm, at time $t_{1}$, the proposed method maintained a fast and stable performance at the MPP.

When the conductance of the PV module was $R_{p v}{ }^{-1}=0.041 \mathrm{~S}, I_{p v}$, Curve2 was 1.47 A according to Eq. (3), whereas the measured value $I_{p v}$ was $1.54 \mathrm{~A}$. Because $I_{p v}>1.025 \cdot I_{p v, \text { Curve2 }}, R_{p v}{ }^{-1}$ and $I_{p v}$ fall on line A (Fig. 4) and correspond to line A.1. From Eq. (4), the irradiance $G$ is $140 \mathrm{~W} / \mathrm{m}^{2}$.

Figure 9(b) shows the test results of the HC algorithm. At time $t_{0}$, MPPT was activated but diverged for $10.8 \mathrm{~s}$, preventing the algorithm from operating at the MPP. However, at time $t_{1}$, the MPPT continued to diverge. In Fig. 9(b), the MPP diverged because of the difficulty in completing the MPPT procedure under a low irradiance level $\left(140 \mathrm{~W} / \mathrm{m}^{2}\right)$, resulting in the confinement of the actuating point at a local minimum. The experimental results in Table 1 verified that the proposed algorithm yielded higher MPPT efficiency, greater output power $P_{o}$, and a shorter convergence time than did the $\mathrm{HC}$ algorithm.

Figure 10 shows the waveforms of the PV output when the proposed and $\mathrm{HC}$ algorithms were used in the MPPT controller for the PV module under irradiance of $65 \mathrm{~W} / \mathrm{m}^{2}$ and a temperature of $20{ }^{\circ} \mathrm{C}$. Figure 10 (a) illustrates the test results of the proposed algorithm. The proposed MPPT algorithm was activated at time $t_{0}$. In the same way, the $V_{p v}$ and $I_{p v}$ sensors delivered measurement signals to the MCU, then the MCU executed the MPPT calculation and sent a 


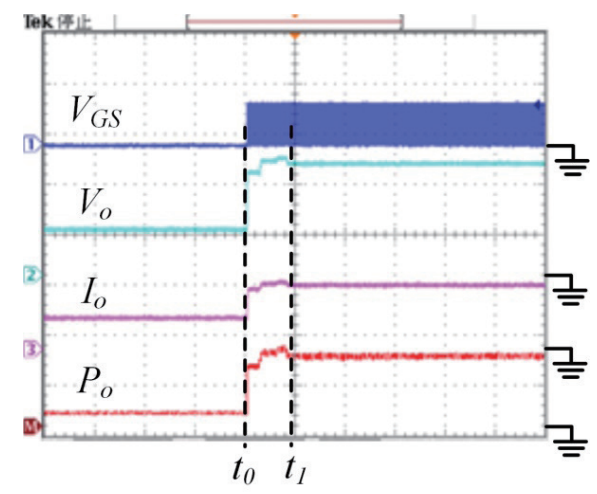

(a)

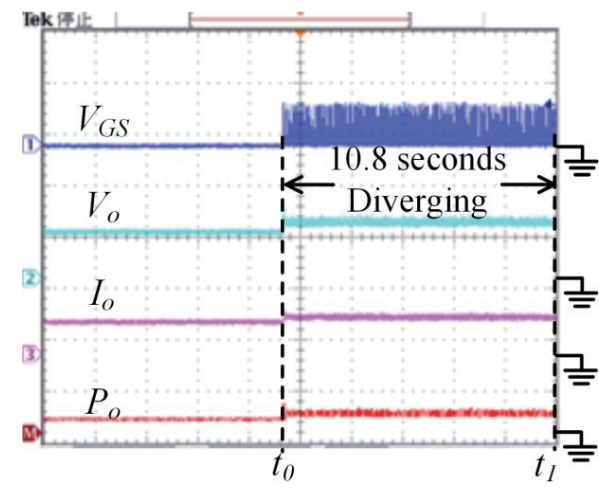

(b)

Fig. 9. (Color online) Waveforms of $V_{G S}, V_{o}, I_{o}$, and $P_{o}$ for the PV module under irradiance of $140 \mathrm{~W} / \mathrm{m}^{2}$ for the proposed algorithm (a) and the $\mathrm{HC}$ algorithm (b). (Ver: $20 \mathrm{~V} / \operatorname{div}$ for $V_{G S} ; 50 \mathrm{~V} / \operatorname{div}$ for $V_{o} ; 0.2 \mathrm{~A} / \operatorname{div}$ for $I_{o} ; 20 \mathrm{~W} / \mathrm{div}$ for $P_{o}$, and Hor: $\left.2 \mathrm{~s} / \mathrm{div}\right)$.

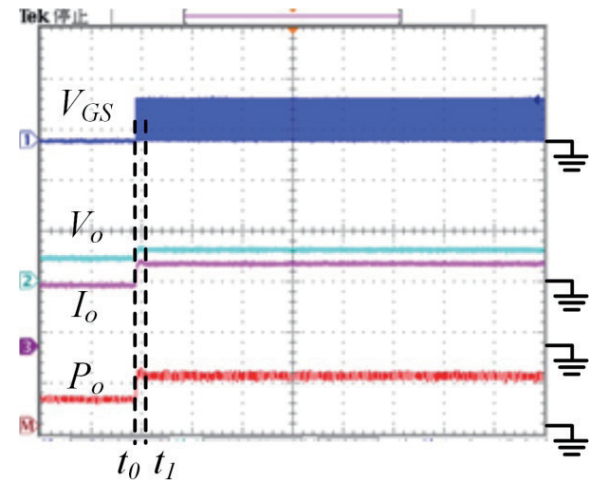

(a)

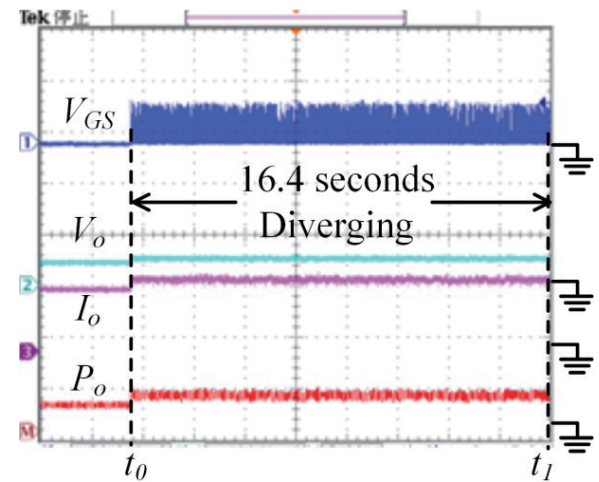

(b)

Fig. 10. (Color online) Waveforms of $V_{G S}, V_{o}, I_{o}$, and $P_{o}$ for the PV module under irradiance of $65 \mathrm{~W} / \mathrm{m}^{2}$ for the proposed algorithm (a) and the $\mathrm{HC}$ algorithm (b). (Ver: $20 \mathrm{~V} / \mathrm{div}$ for $V_{G S} ; 100 \mathrm{~V} / \mathrm{div}$ for $V_{o} ; 0.1 \mathrm{~A} / \operatorname{div}$ for $I_{o} ; 10 \mathrm{~W} / \mathrm{div}$ for $P_{o}$; and Hor: 2 s/div).

Table 1

Comparison of MPPT efficiency, output power, and convergence time.

\begin{tabular}{|c|c|c|c|c|c|c|}
\hline \multirow{2}{*}{$\begin{array}{l}\text { Irradiance level } \\
\left(\mathrm{W} / \mathrm{m}^{2}\right)\end{array}$} & \multicolumn{2}{|c|}{ MPPT efficiency } & \multicolumn{2}{|c|}{ MPPT output power } & \multicolumn{2}{|c|}{ MPPT convergence time } \\
\hline & Proposed (\%) & $\mathrm{HC}(\%)$ & Proposed (W) & $\mathrm{HC}(\mathrm{W})$ & Proposed (s) & $\mathrm{HC}(\mathrm{s})$ \\
\hline 480 & 99 & 70 & 70 & 50 & 0 & 0 \\
\hline 140 & 97 & Divergent & 28 & Divergent & 0 & 10.8 \\
\hline 65 & 90 & Divergent & 10 & Divergent & 0 & 16.4 \\
\hline
\end{tabular}

PWM signal to control the power MOSFET $S_{1}$ (Fig. 7). In contrast to the HC algorithm, at time $t_{1}$, the proposed method could maintain fast and stable performance at the MPP.

When the conductance of the PV module was $R_{p v}{ }^{-1}=0.0189 \mathrm{~S}$, then $I_{p v}$, Curve2 was $0.68 \mathrm{~A}$ from Eq. (3), whereas the measured $I_{p v}$ was $0.72 \mathrm{~A}$. Because $I_{p v}>1.025 \cdot I_{p v}$, Curve $2, R_{p v}{ }^{-1}$ and $I_{p v}$ fall on line A (Fig. 4), corresponding to line A.1 (Fig. 5). From Eq. (4), the irradiance $G$ is $65 \mathrm{~W} / \mathrm{m}^{2}$. 
Figure 10(b) illustrates the test results of the $\mathrm{HC}$ algorithm. At time $t_{0}$, MPPT was activated but diverged for $16.4 \mathrm{~s}$, preventing the algorithm from operating at the MPP; however, MPPT continued to diverge at time $t_{1}$. The MPP in Fig. 10(b) diverged because of the difficulty of completing the MPPT procedure under a low irradiance level $\left(65 \mathrm{~W} / \mathrm{m}^{2}\right)$, resulting in the confinement of the actuating point at a local minimum. The experimental results in Table 1 confirm that the proposed algorithm yielded higher MPPT efficiency, greater output power $P_{o}$, and a shorter convergence time than did the $\mathrm{HC}$ algorithm.

\section{Conclusions}

The proposed algorithm in this study operated consistently at the MPP, even when the PV module was under low irradiance, thus avoiding the power loss due to oscillations around the MPP, which occur in the $\mathrm{HC}$ and $\mathrm{P} \& \mathrm{O}$ algorithms. Experimental results confirmed that the proposed algorithm yielded higher MPPT efficiency for PV modules under irradiance levels of 480,140 , and $65 \mathrm{~W} / \mathrm{m}^{2}$ than did the $\mathrm{HC}$ algorithm. Whereas the $\mathrm{HC}$ and $\mathrm{P} \& \mathrm{O}$ algorithms exhibited difficulties in MPPT for PV modules under low irradiance levels $\left(<150 \mathrm{~W} / \mathrm{m}^{2}\right)$, the proposed algorithm quickly and precisely facilitated MPPT for the PV module under the irradiance level of $65 \mathrm{~W} / \mathrm{m}^{2}$ and substantially improved the module performance under poor weather conditions. Therefore, the proposed algorithm was shown to be highly reliable when used with PV modules under various irradiance levels. More specifically, the proposed algorithm is suitable for long-term low irradiance levels and areas with rapidly changing conditions. However, its performance for MPPT under partial shadow conditions should be improved in the future. Currently, when the irradiance level is insufficient and a solar power generation system cannot supply enough power to the load, users have to switch back to batteries or diesel generators for their power supply. The proposed algorithm can maximize the available power from PV modules in harsh environments to better meet the load demand.

\section{Acknowledgments}

This work was supported by the Ministry of Science and Technology, Taiwan, under contract number MOST 108-2221-E-167-018-MY2 (duration: August 1, 2019-July 31, 2021).

\section{References}

1 I. G. Zurbriggen and M. Ordonez: IEEE Trans. Ind. Electron. 66 (2019) 1852. https://doi.org/10.1109/ TIE.2018.2838115

2 A. D. Martin, J. M. Cano, J. M. García, J. A. G. Galán, and J. R. Vazquez: IEEE Access 8 (2020) 71694. https:// doi.org/10.1109/ACCESS.2020.2987621

3 P. Y. Chen, K. H. Chao, and Y. S. Tsai: Sens. Mater. 31 (2019) 3691. https://doi.org/10.18494/SAM.2019.2200

4 S. Murshid and B. Singh: IEEE Trans. Sustainable Energy 11 (2020) 1323. https://doi.org/10.1109/ TSTE.2019.2924012

5 N. Mutoh, M. Ohno, and T. Inoue: IEEE Trans. Ind. Electron. 53 (2006) 1055. https://doi.org/10.1109/ TIE.2006.878328

6 K. H. Chao, Y. H. Liao, and M. C. Tseng: Sens. Mater. 30 (2018) 2561. https://doi.org/10.18494/SAM.2018.2059

7 B. N. Alajmi, K. H. Ahmed, S. J. Finney, and B. W. Williams: IEEE Trans. Power Electron. 26 (2011) 1022. https://doi.org/10.1109/TPEL.2010.2090903 
8 T. Esram and P. L. Chapman: IEEE Trans. Energy Convers. 22 (2007) 439. https://doi.org/10.1109/ TEC.2006.874230

9 V. P. Nejila and A. I. Selvakumar: IEEE Conf. Power, Energy and Control (2013) 8. https://doi.org/10.1109/ ICPEC.2013.6527614

10 S. Ajay, A. Arunkumar, G. Deepika, S. Maneesha, and R. Ramaprabha: IEEE Texas Instruments India Educators' Conf. (2013) 135. https://doi.org/10.1109/TIIEC.2013.31

11 Y. Hong, S. N. Pham, T. Yoo, K. Chae, K.-H. Baek, and Y. S. Kim: IEEE Trans. Power Electron. 30 (2015) 4209. https://doi.org/10.1109/TPEL.2014.2352314

12 N. Fermia, D. Granozio, G. Petrone, and M. Vitelli: IEEE Trans. Aerospace Electron. Syst. 43 (2007) 934. https://doi.org/10.1109/TAES.2007.4383584

13 C. C. Chen and B. Y. Lin: 2009 8th Information Technology and Applications in Outlying Islands Conf. (ITAO, 2009).

14 A. Ali, K. Almutairi, S. Padmanaban, V. Tirth, S. Algarni, K. Irshad, S. Islam, M. H. Zahir, M. Shafiullah, and M. Z. Malik: IEEE Access 8 (2020) 127368. https://doi.org/10.1109/ACCESS.2020.3007710

15 S. H. Hanzaei, S. A. Gorji, and M. Ektesabi: IEEE Access 8 (2020) 182229. https://doi.org/10.1109/ ACCESS.2020.3028580

16 J. P. Ram, D. S. Pillai, N. Rajasekar, and S. M. Strachan: IEEE J. Emerging Sel. Top. Power Electron. 8 (2020) 1361. https://doi.org/10.1109/JESTPE.2019.2900999

17 J. Ahmed and Z. Salam: IEEE Trans. Sustainable Energy 9 (2018) 1487. https://doi.org/10.1109/ TSTE.2018.2791968

18 H. D. Liu and S. D. Lu: IEICE Electron. Express 16 (2019) 1. https://doi.org/10.1587/elex.16.20190461

19 H. D. Liu, C. H. Lin, and S. D. Lu: IEICE Electron. Express 17 (2020) 1. https://doi.org/10.1587/elex.17.20200099

20 H. D. Liu, C. H. Lin, K. J. Pai, and C. M. Wang: Sol. Energy 198 (2020) 53. https://doi.org/10.1016/j. $\underline{\text { solener.2020.01.049 }}$

21 N. Kumar, I. Hussain, B. Singh, and B. K. Panigrahi: IEEE Trans. Ind. Appl. 54 (2018) 6343. https://doi. org/10.1109/TIA.2018.2853744

22 O. A. Rahim and H. Wang: CPSS Trans. Power Electron. Appl. 5 (2020) 191. https://doi.org/10.24295/ CPSSTPEA.2020.00016

23 M. Killi and S. Samanta: IEEE J. Emerging Sel. Top. Power Electron. 7 (2019) 1399. https://doi.org/10.1109/ JESTPE.2018.2864096 